Article

\title{
The Relationship between Self-Esteem and Achievement Goals in University Students: The Mediating and Moderating Role of Defensive Pessimism
}

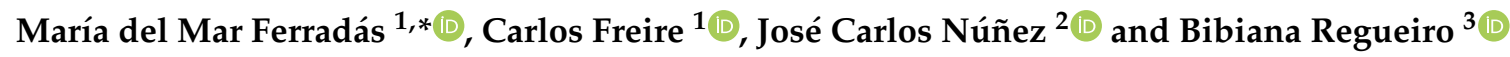 \\ 1 Department of Psychology, University of A Coruña, 15071 A Coruña, Spain; carlos.freire.rodriguez@udc.es \\ 2 Faculty of Psychology, University of Oviedo, 33003 Oviedo, Spain; jcarlosn@uniovi.es \\ 3 Department of Pedagogy and Didactics, University of Santiago de Compostela, \\ 15782 Santiago de Compostela, Spain; bibiana.regueiro@usc.es \\ * Correspondence: mar.ferradasc@udc.es; Tel.: +34-9811670001865
}

Received: 17 August 2020; Accepted: 10 September 2020; Published: 12 September 2020

check for updates

\begin{abstract}
Although achievement goals have been the subject of much study about their implications for learning and performance, interest has been less marked in understanding their precursors, particularly those linked to students' personal characteristics. In this study, we examine the role of a defensive pessimism strategy as a mediator and moderator of the relationships between self-esteem and achievement goals in a sample of 1028 university students. Analysis of mediation and moderation was performed using the PROCESS macro within SPSS. The results showed that defensive pessimism partially mediates and moderates the effect of self-esteem on approach goals (learning and performance). We found no significant mediation or moderation effect for defensive pessimism in the relationship between self-esteem and performance-avoidance goals. These findings suggest that defensive pessimism is an effective strategy to encourage motivational involvement in students with low self-esteem in the academic context.
\end{abstract}

Keywords: self-esteem; achievement goals; defensive pessimism; self-worth; university students

\section{Introduction}

In keeping with the emerging field of the psychology of sustainability and sustainable development [1], in recent years there has been growing interest in the study of personal resources (cognitive, affective, emotional, etc.) that encourage young people's successful adaptation and positive development in the academic environment, despite the difficulties they may encounter [2,3]. In this context, and in light of their significant impact on students' cognitive, affective, and behavioral regulation [4], goals have been the focus of considerable attention in psychoeducational research. One of the most prominent approaches in the study of goals in academic contexts is achievement goal theory (AGT) [5] according to which the motivations and intentions that guide students' involvement in learning underlie how they evaluate competency and success.

From this perspective, AGT makes the distinction between learning goals and performance goals [6]. The former includes those students who judge their competence self-referentially, focusing on developing their own skills as students as much as possible. Students oriented towards performance goals evaluate competency in relation to external standards, prioritizing the demonstration of their academic skills or outperforming their classmates [7].

This initial approach-based differentiation was later extended with the inclusion of equivalent avoidance goals (learning-avoidance goals, and performance-avoidance goals), based on the thinking 
that some students were not oriented towards success, but rather towards avoiding failure and incompetence. Students who adopt learning-avoidance goals focus on preventing loss of previously acquired skills or learning, whereas students with performance-avoidance goals would aim to avoid underperforming their classmates or seeming less competent in the eyes of others [8].

In general, there is consensus about the wide range of emotional and academic benefits of adopting learning-approach goals, in contrast to the greater dysfunctionality of avoidance goals-e.g., use of surface learning strategies, poor persistence in the face of difficulties, little help-seeking, burnout, and poor academic performance [9-14]. The consequences associated with performance-approach goals, however, have been more controversial, even though it seems that this goal orientation produces adaptive results when the student's objective is to outperform their classmates rather than appear highly competent [15].

The significant amount of research about the consequences of adopting the various goal orientations contrasts with the little attention that has been paid to its precursors [16], especially those related to students' personal characteristics. In view of that, in this study, we examine the effect of self-esteem on university students' achievement goals. More specifically, we aim to assess whether this effect is mediated and moderated by the strategy of defensive pessimism.

\subsection{Self-Esteem and Achievement Goals}

Self-esteem refers to how much somebody appreciates and likes themselves and perceives themselves to be a valuable person [17]. This self-referential judgment has a significant impact on personal [18] and academic adjustment [19], both in motivational and performance terms [20,21]. In this regard, self-esteem is a powerful motivator for students to pursue academic goals [22].

Studies in samples of secondary-school [23-25] and university students [26-31] show that self-esteem is positively related to learning-approach goals and negatively related to performance-avoidance goals. However, the relationship between self-esteem and performance-approach goals has thrown up more questions, as both positive $[30,32,33]$ and negative $[31,34]$ relationships have been shown between these variables.

\subsection{The Need to Protect Self-Worth: The Relationship between Self-Esteem and Defensive Pessimism}

As a rule, people with high self-esteem have feelings of self-acceptance and self-worth, which lead them to feel more secure in their own abilities to overcome obstacles and succeed [17]. In contrast, people with low self-esteem usually feel little self-worth, tackling tasks with low self-confidence in succeeding [35]. These individuals, critical of their own worth as people, would be particularly vulnerable in the face of any potential threat to their fragile image of competence [36]. In these conditions, protecting self-esteem may be a priority, motivating some students to proactively adopt complex strategies allowing them to dissociate a possible failure from their self-worth [37].

One of the most widespread self-protective strategies in the academic context is defensive pessimism. Using this mechanism, the student establishes particularly low expectations of success, despite there not being a notable history of failure that would justify such expectations [38]. These unfounded expectations are a self-protective shield for feelings of self-worth [39] in that reduced expectations help the student to effectively manage their anxiety. In effect, this painstaking "thinking through" [40] (p.82) that defensive pessimists do is a motivational spur to prepare and plan how to avoid the failure [41], which often results in good academic performance [42], albeit at the cost of experiencing significant long-term emotional harm [43].

Considering that self-protection is more common in people with low self-esteem [44,45], it seems plausible to think that students with low self-esteem will be more tempted to adopt the strategy of defensive pessimism than students with high self-esteem. The few studies to date seem to suggest this, noting that defensive pessimists usually harbor negative thoughts about themselves [40]. In fact, in comparative terms, students who use this strategy usually exhibit lower levels of self-esteem than optimistic students [46], which would indicate that their assessments of self-esteem are far from high, 
or at least, are unstable [47]. In line with this thesis, Ferradás et al. [48] recently found defensive pessimism to be related to motivational profiles in university students with low self-esteem.

\subsection{Self-Esteem, Defensive Pessimism, and Achievement Goals}

From the motivational perspective, research has attempted to clarify the role of defensive pessimism in students' reasons and purposes for engaging in tasks. In conformance with the motivational duality underlying defensive pessimism, based on the combination of a cognitive commitment to avoiding failure and behavioral involvement in achieving successful performance [49], studies in this regard have associated this strategy with both performance-approach and performance-avoidance goals [47,50-52]. The relationship between defensive pessimism and learning-approach goals is not so clear. Whereas some studies $[47,50]$ report this relationship to be negative, others $[39,48]$ have concluded that in defensively pessimistic students there would be a desire to learn, in combination with intentions (approach and avoidance) to perform.

In light of the reviewed literature, it is possible that in those students who are particularly keen to protect their feelings of self-worth via the use of defensive pessimism this strategy would have a mediating effect between self-esteem and achievement goals. This mediating effect would mean that the relationship between self-esteem and achievement goals would be at least partially indirect, via defensive pessimism. Based on this, and the results of previous research, we have established the following hypotheses (see Figure 1):

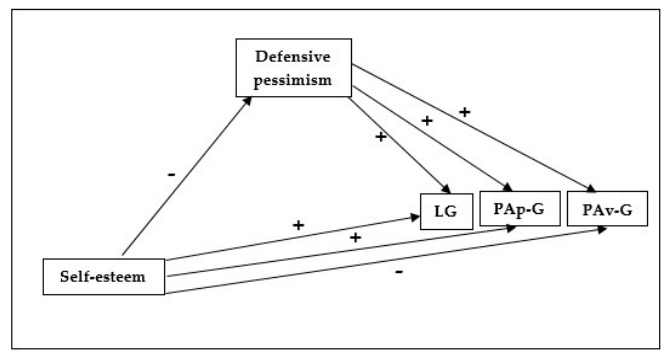

Figure 1. Hypothesized mediational model. LG = learning-approach goals; $P A p-G=$ performance-approach goals; $\mathrm{PAv}-\mathrm{G}=$ performance-avoidance goals.

Hypothesis 1 (H1). Self-esteem will be a negative predictor of defensive pessimism and performance-avoidance goals, and a positive predictor of approach goals (learning and performance).

Hypothesis 2 (H2). Defensive pessimism will be a positive predictor of the three achievement goals considered (learning-approach, performance-approach, and performance-avoidance).

Hypothesis 3 (H3). Self-esteem will have a direct positive effect on learning-approach goals and an indirect negative effect (via defensive pessimism). In other words, the lower the self-esteem, the greater the tendency to use defensive pessimism and the greater the adoption of learning-approach goals.

Hypothesis $4 \mathbf{~ ( H 4 ) . ~ S e l f - e s t e e m ~ w i l l ~ h a v e ~ d i r e c t ~ a n d ~ i n d i r e c t ~ ( v i a ~ d e f e n s i v e ~ p e s s i m i s m ) ~ p o s i t i v e ~ e f f e c t s ~ o n ~}$ performance-approach goals.

Hypothesis 5 (H5). Self-esteem will have direct and indirect (via defensive pessimism) negative effects on performance-avoidance goals.

The proposed hypotheses suggest the possibility that the direction or intensity of the effect of self-esteem on achievement goals are affected by defensive pessimism. This would mean that, in addition to the mediating effect, defensive pessimism has a moderating effect (see Figure 2). In this regard, we propose the following hypotheses: 


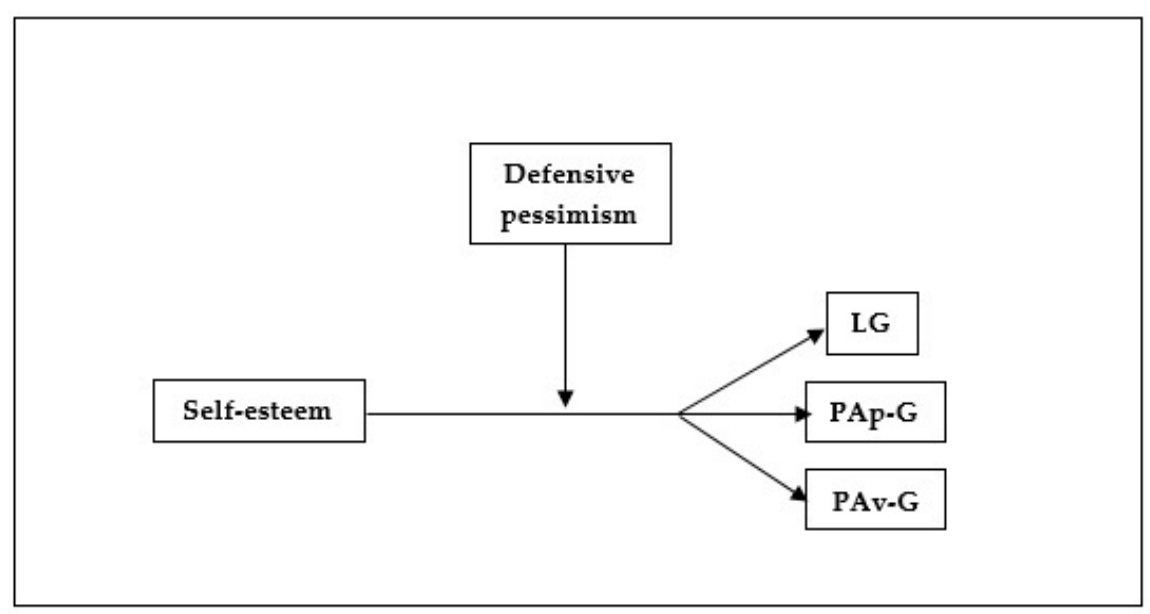

Figure 2. Hypothesized moderation model. LG = learning-approach goals; $P A p-G=$ performance-approach goals; PAv-G = performance-avoidance goals.

Hypothesis 6 (H6). The sign of the relationship between self-esteem and learning-approach goals will be affected by the scores in defensive pessimism: the relationship will be positive for lower values of defensive pessimism and negative for higher values.

Hypothesis 7 (H7). The intensity of the relationship between self-esteem and performance-approach goals will be affected by the scores in defensive pessimism: the relationship will be stronger the higher the values of defensive pessimism.

Hypothesis 8 (H8). The intensity of the relationship between self-esteem and performance-avoidance goals will be affected by the scores in defensive pessimism: the relationship will be stronger the higher the values of defensive pessimism.

\section{Materials and Methods}

\subsection{Participants}

Using convenience sampling, we recruited a sample of 1028 students $\left(M_{\text {age }}=21.36, S D_{\text {age }}=3.81\right.$; 887 women, 141 men) at the University of A Coruña (Spain). Over two-thirds (718; 69.8\%) were studying for bachelor's degrees in education sciences (teaching, social education, and speech therapy) and almost a third (310;30.2\%) were studying healthcare sciences (nursing, podiatry, and physiotherapy). The participants were relatively evenly spread in terms of which year of the course they were on, with $382(37.2 \%)$ in their first year, $334(32.5 \%)$ in their second year, and $312(30.3 \%)$ in their third year.

\subsection{Instruments}

Self-esteem was assessed using the Rosenberg Self-esteem Scale [17], in its validated Spanish version [53]. It is made up of 10 items (e.g., "I feel that I have a number of good qualities") to which participants record their agreement on a five-point Likert-type scale, such that scores closer to five indicate higher levels of self-esteem. In our study, the scale demonstrated internal consistency of $\alpha=0.88$ and $\omega=0.89$ (95\% CI $(0.88,0.90)$ ).

Defensive pessimism was measured using the Spanish adaptation of the Defensive Pessimism Questionnaire (12 items; e.g., "I imagine how I would feel if things went badly") [54]. Responses are recorded on a Likert-type scale from one to five, such that a higher score indicates higher levels of self-reported defensive pessimism. The internal consistency of the instrument in our study was $\alpha=0.89$ and $\omega=0.89(95 \%$ CI $(0.88,0.90))$ 
Achievement goals. The three achievement goals considered in this study were evaluated using the Goal Orientation Scale [33] in its Spanish version [55]. In this scale, learning-approach goals (six items) assess how much the student is focused on learning and understanding tasks (e.g., "What I learn in class makes me want to learn more"). Performance-approach goals (five items) are evaluated in their normative aspect (demonstrating greater competencies than others; e.g., "For me, it is important to manage work that other students cannot manage"). Performance-avoidance goals (six items) are evaluated on the appearance aspect (avoiding negative social judgment; e.g., "For me, the worst thing about making mistakes at university is that other students may notice") according to the characterization of achievement goals by Hulleman et al. [56]. The participants record their responses on a Likert-type scale from one to five, such that scores closer to five indicate greater orientation to the achievement goal assessed. In our study, the three factors demonstrated adequate internal consistency: learning-approach goals, $\alpha=0.79, \omega=0.79(95 \% \mathrm{CI}(0.77,0.81))$; performance-approach goals, $\alpha=0.85$, $\omega=0.85(95 \% \mathrm{CI}(0.83,0.86))$; performance-avoidance goals, $\alpha=0.80, \omega=0.80(95 \% \mathrm{CI}(0.78,0.82))$.

\subsection{Procedure}

We held a meeting with the teachers and managers of the departments and faculties potentially involved in the study to inform them of the study objectives and to request their participation. Once we had their consent, we carried out data collection during normal teaching times. We asked the students for their voluntary, unbiased collaboration, and asked them to answer the questions honestly. We informed them of the confidentiality and anonymity of the information being collected and obtained their written informed consent in compliance with the University of A Coruña ethical research protocols (UDC Ethical Code of Research 27/02/2019) and the Declaration of Helsinki.

\subsection{Data Analysis}

The statistical analysis of the model of mediation-moderation (see Figures 1 and 2) was as follows. First, descriptive statistics were calculated (mean, standard deviation, asymmetry, and kurtosis) along with the (Pearson) correlation matrix for the study variables. Secondly, to test the proposed hypotheses, we performed an analysis of mediation and moderation using the PROCESS macro in the SPSS statistical package [57].

\section{Results}

\subsection{Descriptive Statistics and Analysis of Correlations}

Table 1 gives the descriptive statistics and the Pearson correlation matrix for the variables in the study. The indices of asymmetry and kurtosis indicate that all variables met the criteria for normality [58]. In addition, all of the bivariate correlations were statistically significant $(p<0.001)$. We also performed Bartlett's sphericity test, demonstrating that all of the variables were sufficiently intercorrelated $\left(\chi^{2}(15)=2203.53, p<0.001\right)$.

\subsection{Analysis of Mediation}

The mediating effect of defensive pessimism was assessed via the Bootstrap estimation procedure. Given that estimations of indirect effects do not generally follow a normal distribution, and following the recommendations from MacKinnon et al. [59], we used a Bootstrap sample of 5000 cases and a confidence interval of $95 \%$ to assess the mediation effect. Table 2 shows the direct, indirect, and total effects of the mediation analysis. 
Table 1. Means, standard deviations, asymmetry, kurtosis, and correlations for the study variables.

\begin{tabular}{lccccc}
\hline & $\mathbf{1}$ & $\mathbf{2}$ & $\mathbf{3}$ & $\mathbf{4}$ & $\mathbf{5}$ \\
\hline 1. SE & $-\bar{F}^{* * *}$ & & & & \\
2. DP & $-0.59^{* * *}$ & $0.28^{* * *}$ & - & & \\
3. LG & $-0.12^{* * *}$ & $0.43^{* * *}$ & $-0.18^{* * *}$ & - & \\
4. PApG & $-0.46^{* * *}$ & $0.11^{* * *}$ & $-0.37^{* * *}$ & $0.56^{* * *}$ & - \\
5. PAvG & $-0.22^{* * *}$ & 2.35 & 3.24 & 3.30 & 3.24 \\
M & 3.41 & 0.87 & 1.00 & 0.93 & 0.87 \\
SD & 0.52 & 0.83 & -0.45 & -0.51 & -0.60 \\
Asymmetry & -0.39 & -0.49 & -0.65 & -0.71 & 0.05 \\
Kurtosis & -1.41 &
\end{tabular}

Note: $\mathrm{SE}=$ self-esteem; DP = defensive pessimism; LG = learning-approach goals; PApG = performance-approach goals; $\mathrm{PAvG}=$ performance-avoidance goals; ${ }^{* * *} p<0.001$.

Table 2. Results of mediation analysis.

\begin{tabular}{|c|c|c|c|c|c|c|}
\hline Model Description & Coef. & SE & $t$ & $p$ & LCI & UCI \\
\hline \multicolumn{7}{|l|}{ Dependent variable: $L G$} \\
\hline \multicolumn{7}{|l|}{ Direct effect } \\
\hline $\mathrm{SE} \rightarrow \mathrm{DP}$ & -0.995 & 0.042 & -23.549 & 0.000 & -1.078 & -0.912 \\
\hline $\mathrm{SE} \rightarrow \mathrm{LG}$ & 0.145 & 0.071 & 2.016 & 0.044 & 0.003 & 0.286 \\
\hline $\mathrm{DP} \rightarrow \mathrm{LG}$ & 0.368 & 0.042 & 8.620 & 0.000 & 0.284 & 0.452 \\
\hline \multicolumn{7}{|l|}{ Indirect effect } \\
\hline $\mathrm{SE} \rightarrow \mathrm{DP} \rightarrow \mathrm{LG}$ & -0.367 & 0.049 & - & - & -0.463 & -0.263 \\
\hline Total effect & -0.222 & 0.060 & -3.705 & 0.000 & -0.340 & -0.104 \\
\hline \multicolumn{7}{|l|}{ Dependent variable: PApG } \\
\hline \multicolumn{7}{|l|}{ Direct effect } \\
\hline $\mathrm{SE} \rightarrow \mathrm{PApG}$ & -.557 & 0.060 & -9.203 & 0.000 & -0.676 & -0.438 \\
\hline $\mathrm{DP} \rightarrow \mathrm{PApG}$ & 0.261 & 0.036 & 7.246 & 0.000 & 0.190 & 0.332 \\
\hline \multicolumn{7}{|l|}{ Indirect effect } \\
\hline $\mathrm{SE} \rightarrow \mathrm{DP} \rightarrow \mathrm{PApG}$ & -0.260 & 0.035 & - & - & -0.331 & -0.192 \\
\hline Total effect & -0.818 & 0.050 & -16.345 & 0.000 & -0.916 & -0.719 \\
\hline \multicolumn{7}{|l|}{ Dependent variable: $P A v G$} \\
\hline \multicolumn{7}{|l|}{ Direct effect } \\
\hline $\mathrm{SE} \rightarrow \mathrm{PAvG}$ & -0.388 & 0.063 & -6.090 & 0.000 & -0.513 & -0.263 \\
\hline $\mathrm{DP} \rightarrow \mathrm{PAvG}$ & -0.025 & 0.037 & -0.684 & 0.493 & -0.100 & 0.048 \\
\hline \multicolumn{7}{|l|}{ Indirect effect } \\
\hline $\mathrm{SE} \rightarrow \mathrm{DP} \rightarrow \mathrm{PAvG}$ & 0.025 & 0.035 & - & - & -0.043 & 0.096 \\
\hline Total effect & -0.362 & 0.051 & -7.057 & 0.000 & -0.462 & -0.261 \\
\hline
\end{tabular}

Note: $\mathrm{SE}=$ self-esteem; DP = defensive pessimism; $\mathrm{LG}=$ learning-approach goals; $\mathrm{PApG}=$ performance-approach goals; $\mathrm{PAvG}=$ performance-avoidance goals; $\mathrm{LCI}=$ lower confidence interval $(95 \%)$; $\mathrm{UCI}=$ upper confidence interval (95\%).

With regard to the learning-approach goals, the data confirmed the initial hypothesis stating that defensive pessimism partially mediated the effect of self-esteem on learning goals. In this regard, as Table 2 shows, self-esteem had a significant direct effect both on defensive pessimism and on learning-approach goals. For defensive pessimism, this effect was negative $(b=-0.995 ; p<0.001)$, whereas the effect on learning-approach goals was positive $(b=0.145 ; p<0.05)$. In addition, defensive pessimism had a significant direct positive effect $(b=0.368 ; p<0.001)$ on learning-approach goals. There was also a significant indirect effect of self-esteem on learning-approach goals via defensive pessimism, $(\mathrm{b}=-0.367 ; 95 \% \mathrm{CI}(-0.463,-0.263))$. The confidence interval does not include the value zero, which indicates that this indirect effect was statistically significant. However, unlike the direct effect, in this indirect case, the effect was negative. 
We also confirmed the hypothesized partial mediating effect of defensive pessimism on the relationship between self-esteem and performance-approach goals, although not in the direction we initially hypothesized. Self-esteem had a significant negative effect on performance-approach goals, both directly $(b=-0.557 ; p<0.001)$ and indirectly $(b=-0.260 ; 95 \% \mathrm{CI}(-0.331,-0.192))$. We also found, as expected, a significant direct positive effect of defensive pessimism on performance-approach goals $(b=0.261 ; p<0.001)$.

Finally, the data did not support our initial hypothesis about the partial mediating effect of defensive pessimism on performance-avoidance goals. We found that self-esteem had a significant direct negative effect on performance-avoidance goals $(b=-0.388 ; p<0.001)$, but there was no indirect effect through defensive pessimism $(b=0.025 ; 95 \% \mathrm{CI}(-0.043,-0.096))$. In this latter case, the confidence interval includes zero, indicating that the indirect effect was not statistically significant. In addition, we saw no significant direct effect of defensive pessimism on performance-avoidance goals $(b=-0.025 ; p>0.05)$, although the total effect of the model was statistically significant $(b=-0.362$; $p<0.001)$.

\subsection{Analysis of Moderation}

The next step was to analyze the role of defensive pessimism as a moderator of the relationship between self-esteem and achievement goals. The aim was to examine whether the strength or direction of this relationship was significantly affected by the scores for defensive pessimism. The results of this moderation analysis are presented in Table 3.

Table 3. Results of moderation analysis.

\begin{tabular}{|c|c|c|c|c|c|c|}
\hline Model Description & Coef. & SE & $t$ & $p$ & LCI & UCI \\
\hline \multicolumn{7}{|l|}{ Dependent variable: $\mathrm{LG}$} \\
\hline $\mathrm{SE} \times \mathrm{DP} \rightarrow \mathrm{LG}$ & -0.457 & 0.083 & -5.493 & 0.000 & -0.621 & -0.294 \\
\hline \multicolumn{7}{|c|}{ Conditional effect of SE on LG for different values of the moderator (DP) } \\
\hline $\mathrm{DP}=1.545$ & 0.490 & 0.094 & 5.174 & 0.000 & 0.304 & 0.675 \\
\hline $\mathrm{DP}=2.000$ & 0.282 & 0.075 & 3.754 & 0.000 & 0.134 & 0.430 \\
\hline $\mathrm{DP}=3.545$ & -0.425 & 0.125 & -3.381 & 0.000 & -0.671 & -0.178 \\
\hline \multicolumn{7}{|l|}{$\begin{array}{l}\text { Dependent variable: } \\
\text { PApG }\end{array}$} \\
\hline $\mathrm{SE} \times \mathrm{DP} \rightarrow \mathrm{PApG}$ & -0.287 & 0.070 & -4.066 & 0.000 & -0.426 & -0.148 \\
\hline \multicolumn{7}{|c|}{ Conditional effect of SE on PApG for different values of the moderator (DP) } \\
\hline $\mathrm{DP}=1.545$ & -.340 & 0.080 & -4.240 & 0.000 & -0.498 & -0.183 \\
\hline $\mathrm{DP}=2.000$ & -0.471 & 0.063 & -7.392 & 0.000 & -0.596 & -0.346 \\
\hline $\mathrm{DP}=3.545$ & -0.915 & 0.106 & -8.590 & 0.000 & -1.124 & -0.706 \\
\hline \multicolumn{7}{|l|}{$\begin{array}{c}\text { Dependent variable: } \\
\text { PAvG }\end{array}$} \\
\hline $\mathrm{SE} \times \mathrm{DP} \rightarrow \mathrm{PAvG}$ & 0.103 & 0.074 & 1.386 & 0.165 & -0.043 & 0.250 \\
\hline
\end{tabular}

Note: $\mathrm{SE}=$ self-esteem; DP = defensive pessimism; $\mathrm{LG}=$ learning-approach goals; $\mathrm{PApG}=$ performance-approach goals; $\mathrm{PAvG}$ = performance-avoidance goals; $\mathrm{LCI}=$ lower confidence interval $(95 \%) ; \mathrm{UCI}=$ upper confidence interval (95\%).

In terms of the moderating effect of defensive pessimism on the relationship between self-esteem and learning-approach goals, we found that this effect (SE $x$ DP) was statistically significant $(b=-0.457$; $\mathrm{p}<0.001$ ) and significantly increased the variance explained by self-esteem (change in $R^{2}=0.026$, $\mathrm{F}(1,1024)=30.182, p<0.001)$. On examining the conditional effect of self-esteem on learning-approach goals as a function of the values for defensive pessimism, the data confirmed our hypothesis about this effect being positive and significant with low $(b=0.490 ; p<0.001)$ or moderate $(b=0.282 ; p<0.001)$ scores in defensive pessimism, and negative and significant with high scores in defensive pessimism $(b=-0.425 ; p<0.001)$. 
With the performance-approach goals, there was an interaction effect between self-esteem and defensive pessimism for this type of achievement goal $(b=-0.287 ; p<0.001)$. There was a statistically significant increase in the variance explained by self-esteem on the inclusion of defensive pessimism as a moderator (change $\mathrm{R}^{2}=0.012, \mathrm{~F}(1,1024)=16.539, p<0.001$ ). The conditional effect of self-esteem on performance-approach goals was statistically significant for all the values of defensive pessimism examined, and the effect was progressively stronger the higher the score in defensive pessimism.

The data did not confirm our hypothesis regarding the moderating effect of defensive pessimism in the relationship between self-esteem and performance-avoidance goals $(b=0.103 ; p>0.05)$. The increase in variance explained by self-esteem on the introduction of defensive pessimism as a moderating variable was not statistically significant (change in $\mathrm{R}^{2}=0.001, \mathrm{~F}(1,1024)=1.923, p>0.05$ ).

\section{Discussion}

In this study, we examined the roles of self-esteem and defensive pessimism as determinants of the three most commonly studied achievement goals in the academic environment-learning-approach, performance-approach, and performance-avoidance [24]. With the extent to which self-esteem has been found to be closely linked to feelings of self-worth [17], it seems important to study how far the need to protect self-esteem can significantly influence the relationship between students' judgments about themselves and the achievement goals they adopt. With that intention, our study analyzed the role of defensive pessimism specifically as a mediator and moderator in that relationship.

Our results showed that, in line with our initial hypothesis, self-esteem has a direct effect on both defensive pessimism and achievement goals. The effect is negative on defensive pessimism, suggesting that the lower the self-esteem, the greater the likelihood of students adopting defensive pessimism as a strategy and vice versa. This finding is consistent with previous research $[40,46,48]$ and confirms the thesis that people with low self-esteem are more inclined to self-protect their self-worth [44,45].

The results also showed, in line with expectations, self-esteem to have a significant positive direct effect on learning-approach goals, and a negative effect on performance-avoidance goals. These findings suggest that, as noted by other studies [26,27,29-31], high self-esteem encourages students' desire to involve themselves in academic activity in order to improve their skills and abilities. In contrast, students with low self-esteem, thus, critical of their own self-worth, seek to avoid socially exposing their, self-perceived, poor competence.

On the other hand, with respect to the direct effect of self-esteem on performance-approach goals, in contrast to our hypothesis, we found a significant negative effect. Previous studies have produced inconsistent results about the relationship between these variables, showing both positive [30,32,33] and negative [31,34] relationships. Our data seem to align with the latter position. Assuming that in our study, the performance-approach goals were evaluated with a normative approach (demonstrating that one is more capable than other classmates), it seems that beneath this need to appear competent lies weak self-esteem which would need to be bolstered by achieving a good performance which would allow others to see greater competence. However, students with high self-esteem would not be as concerned about demonstrating their competence as much as developing it, which would explain its weaker involvement in performance-approach goals.

Our results indicate that self-esteem has not only a direct effect on achievement goals, but also an indirect effect through defensive pessimism. In this regard, we confirmed our hypothesis about the mediating and moderating role of this self-protective strategy, albeit only partially, as this mediating and moderating effect was not evident in all of the cases we expected.

With learning-approach goals, the data indicate that defensive pessimism partially mediates the effect of self-esteem on this motivational orientation, however, the sign of the effect is the opposite of the direct effect. This indicates that, although low self-esteem would directly inhibit orientation towards learning-approach goals, in those students who adopt a strategy of defensive pessimism to safeguard their self-worth against potential failure, the desire for learning and enhancing academic competencies continues to be high. In fact, the results of the moderation analysis confirm that the use of defensive 
pessimism significantly changes the sign of the relationship between self-esteem and learning-approach goals such that, when this self-protective strategy is not used, or is not used diligently, low self-esteem would be a negative predictor of motivation to learn. However, low self-esteem would not be an obstacle to students involving themselves in academic tasks in order to learn for those who regularly resort to defensive pessimism.

The mediating and moderating role of defensive pessimism in the relationship between self-esteem and learning-approach goals seems to indicate that although this strategy is usually "activated" in ego-threatening situations [60], those where there is a strong concern about performance, in defensive pessimists, despite their low self-esteem, there is a desire for personal improvement, as has been noted in some previous studies $[39,48,54]$. Therefore, in the light of our findings, defensive pessimism is a strategic mechanism for students with low self-esteem to face academic work with the desire to improve their own skills as students.

With performance-approach goals, our results support the mediating and moderating role of defensive pessimism on the effect of self-esteem on this motivational orientation, although not in the hypothesized sense. Both directly and via the adoption of defensive pessimism, low self-esteem encourages students' tendencies to involve themselves in their work with the desire to stand out academically. In addition, this tendency would be significantly stronger the more the student adopted defensive pessimism. This finding gives rise to various readings. On the one hand, it seems that the desire to achieve is present in students who adopt the strategy of defensive pessimism [50,51], to the extent that outperforming their classmates is used as a reference point to calibrate their own competence as students [39]. On the other hand, it is possible that defensively pessimistic students strategically use their self-referential negative thoughts as motivation to work hard in order to avoid the failure that they predict they will suffer $[47,61]$, which would explain their orientation towards performance-approach goals.

Finally, contrary to our hypothesis, the data do not support the mediating and moderating role of defensive pessimism in the relationship between self-esteem and performance-avoidance goals. More specifically, our data show the effect of self-esteem on this goal orientation to only be direct, and defensive pessimism is not a significant predictor of performance-avoidance goals. This was a surprising result, as previous research $[51,52,62]$ has stressed the existence of a motivational pattern of performance-avoidance in students who were defensively pessimistic. It is possible that the discrepancy between our findings and those from other studies is more about the operationalization of the performance-avoidance goals in our study (i.e., avoiding negative social judgment about one's competence). In this regard, it seems that underlying the fear of poor performance displayed by defensive pessimists there is a self-protective motive rather than a concern about the negative opinions of others [63]. Consequently, future studies should examine whether defensive pessimism could mediate and/or moderate the relationship between self-esteem and performance-avoidance goals when the latter alludes to a genuine concern about avoiding performing below certain self-imposed standards.

\subsection{Psycho-Educational and Health Implications}

Our study has some significant psycho-educational and health implications. The data seem to indicate that low self-esteem in itself would reduce students' tendencies to involve themselves in academic activity with approach intent for learning reasons. In contrast, low self-esteem would foster cognitive, affective, and behavioral involvement in the students focused on their social image of competence (either pursuing performance-approach or performance-avoidance goals). To the extent that these goal tendencies usually bring with them significant academic and/or emotional harm for the student $[9,12,13,15]$, low self-esteem is a motivational risk factor.

However, our findings suggest that defensive pessimism could be an effective strategic mechanism for students with low self-esteem to encourage their approach involvement in academic work, whether with the intention of self-improvement or achieving good performance. Considering the academic benefits of these two goal orientations, one might assume that defensive pessimism is 
a particularly adaptive strategy for students with low self-esteem. In fact, defensive pessimism is associated with high levels of effort, deep learning, and self-regulation in the academic context $[46,64,65]$.

That said, in order to assess the fitness of defensive pessimism, it is essential to bear in mind the notable harm to the students' psychological health that using it repeatedly can cause in the long term $[41,43,66]$. These damaging effects not only move defensive pessimism away from being considered an optimal regulation strategy [50], they also justify the need to pay specific psychological attention to these university students, as other studies have noted [67] in accordance with the importance placed on the promotion of wellbeing and good health in all stages of life, established in Sustainable Development Goal n 3 [68].

In this regard, some psycho-educational guidelines have been suggested that improve perceived control, at the same time as reducing evaluative threat, and with that the need for students to prioritize protecting their self-worth $[39,69,70]$. Measures that teachers can take include: (a) encouraging teaching-learning processes that stimulate individual improvement and cooperative learning (rather than competition), (b) emphasize the students' worth regardless of their academic performance (e.g., their personal strengths), (c) be explicit about the processes the students should follow to satisfactorily complete tasks and achieve set objectives, and (d) encourage the students to analyze their results in light of their efforts and their proper or improper use of strategies (rather than attributing this to personal capability). Through these initiatives, the student would develop a set of essential personal skills and resources for effectively managing their day-to-day problems and challenges [71]. To the extent that they encourage adaptive personal and professional development, these types of "soft skills" [72] would, in short, contribute to quality education, set out as one of the supporting pillars of the 2030 Agenda for Sustainable Development [68].

\subsection{Limitations of the Study and Future Lines of Research}

The contributions from this study should be weighed in light of some limitations. Firstly, it is not possible to determine causal relationships using a transversal study. New studies are needed which investigate this possible causal link using more rigorous designs (e.g., longitudinal designs). Secondly, the sampling procedure limits the possible extrapolation of the findings to the university students' population as a whole. Thirdly, the exclusive use of self-report measures may mean biases in obtaining valid, reliable data, which means that more studies are needed to compare this study's findings using complementary data collection methods (e.g., thorough interviews with students and teachers, observation scales). Finally, it is important to note that defensive pessimism is not the only self-protective strategy used in the academic context; future studies should investigate the role played by other strategies (e.g., self-handicapping) in mediating or moderating the relationships between self-esteem and achievement goals. With regard to these latter points, it would also be interesting for future research to analyze the effect of self-esteem and self-protective strategies for self-worth on other goal orientations that have been less studied, but which also apply in the academic context (e.g., learning-avoidance goals, work-avoidance goals, social goals).

\section{Conclusions}

This study's main contribution is the identification of defensive pessimism as a mediating and moderating self-protection strategy in the relationship between student self-esteem and the achievement goals that they adopt in the academic context. Specifically, our findings indicate that students with low self-esteem who make a lot of use of defensive pessimism are significantly oriented towards learning, as well as towards performing at a high level. However, their orientation towards performance-avoidance goals is significantly reduced. Given this, defensive pessimism can be assumed to be a motivationally adaptive self-protection strategy for students with low self-esteem. 
Author Contributions: Conceptualization, M.d.M.F. and C.F.; Methodology, M.d.M.F., C.F., and J.C.N.; Formal analysis, M.d.M.F., C.F., and J.C.N.; Investigation, M.d.M.F., C.F., and J.C.N.; Writing-original draft preparation, M.d.M.F., C.F., and B.R.; Writing-review and editing, M.d.M.F., C.F., and B.R.; Supervision, M.d.M.F., C.F., and B.R. All authors have read and agreed to the published version of the manuscript.

Funding: This work was partially funded by the European Regional Development Funds (European Union and Principality of Asturias) through the Science, Technology and Innovation Plan (FC-GRUPIN-IDI/2018/000199).

Acknowledgments: The authors are grateful to the students who participated in the study.

Conflicts of Interest: The authors declare no conflict of interest.

\section{References}

1. Di Fabio, A. The psychology of sustainability and sustainable development for well-being in organizations. Front. Psychol. 2017, 8, 1534. [CrossRef]

2. Dvorsky, M.R.; Kofler, M.J.; Burns, G.L.; Luebbe, A.M.; Garner, A.A.; Jarrett, M.A.; Soto, E.F.; Becker, S.P. Factor structure and criterion validity of the five $\mathrm{Cs}$ model of positive youth development in a multi-university sample of college students. J. Youth Adolesc. 2019, 48, 537-553. [CrossRef] [PubMed]

3. Savickas, M.L.; Porfeli, E.J. Career adaptabilities scale: Construction, reliability, and measurement equivalence across 13 countries. J. Vocat. Behav. 2012, 80, 661-673. [CrossRef]

4. Senko, C. Achievement goal theory: A story of early promises, eventual discords, and future possibilities. In Handbook of Motivation at School; Wentzel, K., Miele, D., Eds.; Taylor \& Francis: New York, NY, USA, 2016; Volume 2, pp. 75-95.

5. Dweck, C.S.; Leggett, E.L. A social-cognitive approach to motivation and personality. Psychol. Rev. 1988, 95, 256-273. [CrossRef]

6. Elliot, A.J. Approach and avoidance motivation and achievement goals. Educ. Psychol. 1999, 34, 169-189. [CrossRef]

7. Kaplan, A.; Maehr, M.L. The contributions and prospects of goal orientation theory. Educ. Psychol. Rev. 2007, 19, 141-184. [CrossRef]

8. Elliot, A.J.; McGregor, H.A. A 2x2 achievement goal framework. J. Pers. Soc. Psychol. 2001, 80, 501-519. [CrossRef]

9. Alhadabi, A.; Karpinski, A.C. Grit, self-efficacy, achievement orientation goals, and academic performance in University students. Int. J. Adolesc. Youth 2020, 25, 519-535. [CrossRef]

10. Duchesne, S.; Larose, S.; Feng, B. Achievement goals and engagement with academic work in early high school: Does seeking help from teachers matter? J. Early Adolesc. 2019, 39, 222-252. [CrossRef]

11. Duchesne, S.; Ratelle, C.F. Achievement goals, motivations, and social and emotional adjustment in high school: A longitudinal mediation test. Educ. Psychol. 2020. [CrossRef]

12. Nadon, L.; Babenko, O.; Chazan, D.; Daniels, L.M. Burning out before they start? An achievement goal theory perspective on medical and education students. Soc. Psychol. Educ. 2020. [CrossRef]

13. Van Yperen, N.W.; Blaga, M.; Postmes, T. A meta-analysis of the impact of situationally induced achievement goals on task performance. Hum. Perform. 2015, 28, 165-182. [CrossRef]

14. Van Yperen, N.W.; Elliot, A.J.; Anseel, F. The influence of mastery-avoidance goals on performance improvement. Eur. J. Soc. Psychol. 2009, 39, 932-943. [CrossRef]

15. Senko, C.; Dawson, B. Performance-approach goal effects depend on how they are defined: Meta-analytic evidence from multiple educational outcomes. J. Educ. Psychol. 2017, 109, 574-598. [CrossRef]

16. King, R.B.; Mendoza, N.B. Achievement goal contagion: Mastery and performance goals spread among classmates. Soc. Psychol. Educ. 2020, 23, 795-814. [CrossRef]

17. Rosenberg, M. Society and the Adolescent Self-Image; Princeton University: Princeton, NJ, USA, 1965.

18. Soto-Sanz, V.; Piqueras, J.A.; Rodríguez-Marín, J.; Pérez-Vázquez, M.T.; Rodríguez-Jiménez, T.; Castellví, P.; Miranda-Mendizábal, A.; Parés-Badell, O.; Almenara, J.; Blasco, M.J.; et al. Self-esteem and suicidal behavior in youth: A meta-analysis of longitudinal studies. Psicothema 2019, 31, 246-254.

19. Reason, R.D.; Terenzini, P.T.; Domingo, R.J. First things first: Developing academic competence in the first year of college. Res. High. Educ. 2006, 47, 149-175. [CrossRef] 
20. Li, J.; Han, X.; Wang, W.; Sun, G.; Cheng, Z. How social support influences university students' academic achievement and emotional exhaustion: The mediating role of self-esteem. Learn. Indiv. Differ. 2018, 61, 120-126. [CrossRef]

21. Topçu, S.; Leana-Taşcılar, M.Z. The role of motivation and self-esteem in the academic achievement of Turkish gifted students. Gift. Educ. Int. 2018, 34, 3-18. [CrossRef]

22. Fang, L. Educational aspirations of Chinese migrant children: The role of self-esteem contextual and individual influences. Learn. Indiv. Differ. 2016, 50, 195-202. [CrossRef]

23. Mastrotheodoros, S.; Talias, M.A.; Motti-Stefanidi, F. Goal orientation profiles, academic achievement and well-being of adolescents in Greece. In Well-Being of Youth and Emerging Adults Across Cultures. CROSS-Cultural Advancements in Positive Psychology; Dimitrova, R., Ed.; Springer: Cham, Switzerland, 2017; Volume 12, pp. 105-120.

24. Meier, A.M.; Reindl, M.; Grassinger, R.; Berner, V.D.; Dresel, R. Development of achievement goals across the transition out of secondary school. Int. J. Educ. Res. 2013, 61, 15-25. [CrossRef]

25. Tuominen-Soini, H.; Salmela-Aro, K.; Niemivirta, M. Achievement goal orientations and subjective well-being: A person-centred analysis. Learn. Instr. 2008, 18, 251-266. [CrossRef]

26. Chen, Z.; Sun, K.; Wang, K. Self-Esteem, achievement goals, and self-handicapping in college physical education. Psychol. Rep. 2018, 121, 690-704. [CrossRef]

27. Gębka, B. Psychological determinants of university students' academic performance: An empirical study. J. Furth. High. Educ. 2014, 38, 813-837. [CrossRef]

28. Heimpel, S.A.; Elliot, A.J.; Wood, J.V. Basic personality dispositions, self-esteem, and personal goals: An approach-avoidance analysis. J. Pers. 2006, 74, 1293-1320. [CrossRef] [PubMed]

29. Komarraju, M.; Dial, C. Academic identity, self-efficacy, and self-esteem predict self-determined motivation and goals. Learn. Indiv. Differ. 2014, 32, 1-8. [CrossRef]

30. Phan, H.P. Students' academic performance and various cognitive processes of learning: An integrative framework and empirical analysis. Educ. Psychol. 2010, 30, 297-322. [CrossRef]

31. Shim, S.S.; Ryan, A.M.; Cassady, J. Changes in self-esteem across the first year in college: The role of achievement goals. Educ. Psychol. 2012, 32, 149-167. [CrossRef]

32. Cetinkalp, Z.K. Achievement goals and physical self-perceptions of adolescent athletes. Soc. Behav. Pers. 2012, 40, 473-480. [CrossRef]

33. Skaalvik, E.M. Self-enhancing and self-defeating ego orientation: Relations with task avoidance orientation, achievement, self-perceptions, and anxiety. J. Educ. Psychol. 1997, 89, 71-81. [CrossRef]

34. Ahmed, M.D.; Yan Ho, W.K.; Van Niekerk, R.L.; Morris, T.; Elayaraja, M.; Lee, K.-C.; Randles, E. The self-esteem, goal orientation, and health-related physical fitness of active and inactive adolescent students. Cogent Psychol. 2017, 4, 1331602. [CrossRef]

35. Jones, A.M.; Buckingham, J.T. Self-esteem as a moderator of the effect of social comparison on women's body image. J. Soc. Clin. Psychol. 2005, 24, 1164-1187. [CrossRef]

36. Covington, M.V. Making the Grade: A Self-Worth Perspective on Motivation and School Reform; Cambridge University Press: New York, NY, USA, 1992.

37. De Castella, K.; Byrne, D.; Covington, M.V. Unmotivated or motivated to fail? A cross-cultural study of achievement motivation, fear of failure, and student disengagement. J. Educ. Psychol. 2013, 105, 861-880. [CrossRef]

38. Norem, J.K. Defensive pessimism as a self-critical tool. In Self-Criticism and Self-Enhancement: Theory, Research and Clinical Applications; Chang, E.C., Ed.; American Psychological Association: Washington, DC, USA, 2008; pp. 89-104.

39. Martin, A.J.; Marsh, H.W.; Williamson, A.; Debus, R.L. Self- handicapping, defensive pessimism and goal orientation: A qualitative study of university students. J. Educ. Psychol. 2003, 95, 617-628. [CrossRef]

40. Norem, J.K. Defensive pessimism, optimism, and pessimism. In Optimism and Pessimism: Implications for Theory, Research, and Practice; Chang, E.C., Ed.; American Psychological Association: Washington, DC, USA, 2001; pp. 77-100.

41. Seery, M.; West, T.; Weisbuch, M.; Blascovich, J. The effects of negative reflection for defensive: Dissipation or harnessing of threat? Pers. Indiv. Differ. 2008, 45, 515-520. [CrossRef] 
42. Nob, R.M.; Bumanglag, A.M.L.; Diwa, G.M.; Ponce, G.I. The moderating role of defensive pessimism in the relationship between test anxiety and performance in a licensure examination. Educ. Meas. Eval. Rev. 2018, 9, 68-83.

43. Norem, J.K.; Chang, E.C. A very full glass: Adding complexity to our thinking about the implications and applications of optimism and pessimism research. In Optimism and Pessimism: Implications for Theory, Research, and Practice; Chang, E.C., Ed.; American Psychological Association: Washington, DC, USA, 2001; pp. 347-367.

44. Baumeister, R.F.; Tice, D.M.; Hutton, D.G. Self-presentational motivations and personality differences in self-esteem. J. Pers. 1989, 57, 547-579. [CrossRef]

45. Tice, D.M. Esteem protection or enhancement? Self-handicapping motives and attributions differ by trait self-esteem. J. Pers. Soc. Psychol. 1991, 60, 711-725. [CrossRef]

46. Eronen, S.; Nurmi, J.; Salmela-Aro, K. Optimistic, defensive pessimistic, impulsive, and self-handicapping strategies in university environments. Learn. Instr. 1998, 8, 159-177. [CrossRef]

47. Yamawaki, N.; Tschanz, B.T.; Feick, D.L. Defensive pessimism, self-esteem instability and goal strivings. Cogn. Emot. 2004, 18, 233-249. [CrossRef]

48. Ferradás, M.M.; Freire, C.; Núñez, J.C.; Regueiro, B. Associations between profiles of self-esteem and achievement goals and the protection of self-worth in university students. Int. J. Environ. Res. Public Health 2019, 16, 2218. [CrossRef]

49. Martin, A.J.; Marsh, H.W. Fear of failure: Friend or foe? Aust. Psychol. 2003, 38, 31-38. [CrossRef]

50. Elliot, A.J.; Church, M. A motivational analysis of defensive pessimism and self-handicapping. J. Pers. 2003, 71, 369-396. [CrossRef] [PubMed]

51. Ferradás, M.M.; Freire, C.; Regueiro, B.; Valle, A. Defensive pessimism, self-esteem and achievement goals: A person-centered approach. Psicothema 2018, 30, 53-58.

52. Rodríguez, S.; Cabanach, R.G.; Valle, A.; Núñez, J.C.; González-Pienda, J.A. Differences in use of self-handicapping and defensive pessimism and its relation with achievement goals, self-esteem, and self-regulation strategies. Psicothema 2004, 16, 625-631.

53. Martín-Albo, J.; Núñez, J.L.; Navarro, J.G.; Grijalvo, F. The Rosenberg Self-Esteem Scale: Translation and validation in university students. Span. J. Psychol. 2007, 10, 458-467. [CrossRef]

54. Norem, J.K. El Poder Positivo del Pensamiento Negativo: Utiliza el Pesimismo Defensivo para Reducir tu Ansiedad y Rendir al Máximo [The Positive Power of Negative Thinking: Using Defensive Pessimism to Harness Anxiety and Perform at Your Peak]; Paidos: Barcelona, Spain, 2002.

55. Jover, I.; Navas, L.; Holgado, F.P. Goal orientations in the students of the Education Faculty of Alicante. Int. J. Dev. Educ. Psychol. 2014, 1, 575-584.

56. Hulleman, C.S.; Schrager, S.M.; Bodman, S.M.; Harackiewicz, J.M. A meta-analytic review of achievement goal measures: Different labels for the same constructs or different constructs with similar labels? Psychol. Bull. 2010, 136, 422-449. [CrossRef]

57. Hayes, A.F. Introduction to Mediation, Moderation and Conditional Process Analysis. A Regression Based Approach; Guilford Press: New York, NY, USA, 2013.

58. Finney, S.J.; DiStefano, C. Non-normal and categorical data in structural equation modelling. In Structural Equation Modelling. A Second Course; Hancock, G.R., Mueller, R.O., Eds.; Information Age Publishing: Greenwich, CT, USA, 2006; pp. 269-314.

59. MacKinnon, D.P.; Lockwood, C.M.; Williams, J. Confidence limits for the indirect effect: Distribution of the product and resampling methods. Multivar. Behav. Res. 2004, 39, 99. [CrossRef]

60. Thompson, T.; Le Fevre, C. Implications of manipulating anticipatory attributions on the strategy use of defensive pessimists and strategic optimists. Pers. Indiv. Differ. 1999, 26, 887-904. [CrossRef]

61. Norem, J.K.; Smith, S. Defensive pessimism: Positive past, anxious present, and pessimistic future. In Judgments over Time: The Interplay of Thoughts, Feelings, and Behaviors; Sanna, L.J., Chang, E.C., Eds.; Oxford University Press: Oxford, UK, 2006; pp. 34-46.

62. Martin, A.J.; Marsh, H.W.; Debus, R.L. Self-handicapping and defensive pessimism: Exploring a model of predictors and outcomes from a self-protection perspective. J. Educ. Psychol. 2001, 93, 87-102. [CrossRef]

63. Norem, J.K.; Illingworth, K.S.S. Strategy dependent effects of reflecting on self and tasks: Some implications of optimism and defensive pessimism. J. Pers. Soc. Psychol. 1993, 65, 822-835. [CrossRef]

64. Cano, F.; Martin, A.J.; Ginns, P.; Berbén, A.B.G. Students' self-worth protection and approaches to learning in higher education: Predictors and consequences. High. Educ. 2018, 76, 163-181. [CrossRef] 
65. Suárez, J.M. Optimistic and defensive-pessimist students: Differences in their academic motivation and learning strategies. Span. J. Psychol. 2014, 17, e26. [CrossRef] [PubMed]

66. Lee, J.-Z.; Chen, C.-Y.; Liang, T.-L. A motivational analysis of defensive pessimist and long-term wellbeing after achievement feedback. Bull. Educ. Psychol. 2010, 41, 733-749.

67. Fernández-Rodríguez, C.; Soto-López, T.; Cuesta, M. Needs and demands for psychological care in university students. Psicothema 2019, 31, 414-421.

68. UN General Assembly. Transforming our World: The 2030 Agenda for Sustainable Development; United Nations: New York, NY, USA, 2015; pp. 1-35. Available online: https://www.refworld.org/docid/57b6e3e44.html (accessed on 30 August 2020).

69. Gustems-Carnicer, J.; Calderón, C. Virtues and character strengths related to approach coping strategies of college students. Soc. Psychol. Educ. 2016, 19, 77-95. [CrossRef]

70. Thompson, T. Underachieving to Protect Self-Worth. Theory, Research and Interventions; Routledge: London, UK, 2018.

71. Anthony, S.; Garner, B. Teaching Soft Skills to Business Students. Bus. Prof. Commun. Q 2016, 79, 360-370. [CrossRef]

72. Caggiano, V.; Schleutker, K.; Petrone, L.; González-Bernal, J. Towards identifying the soft skills needed in curricula: Finnish and Italian students' self-evaluations indicate differences between groups. Sustainability 2020, 12, 4031. [CrossRef]

(C) 2020 by the authors. Licensee MDPI, Basel, Switzerland. This article is an open access article distributed under the terms and conditions of the Creative Commons Attribution (CC BY) license (http://creativecommons.org/licenses/by/4.0/). 